\title{
Assistive Technology for Visually Impaired People using Li-Fi
}

\author{
Senthamil Selvi M, Nivedita S, Ramya M, Sunija S
}

\begin{abstract}
Blind people faces lot of difficulties in day to day life. While walking they may struggle during their pathway. Some of the blinds they may use the external things to guide their path. When they were in indoor systems they may not aware of certain places inside their home. They prefer the help of another people to guide their way, instead there is an Li-Fi technology used only for indoor navigation purpose. By using of transmitter and receiver systems it allows them to guide in a proper path. Using voice recognition, the system helps to move from one places to another places inside the home. This project works only through the visible light as a source for communication. So by using this project we trained those blind people to navigate their path in an proper way.
\end{abstract}

Key Terms - light source, Li-Fi transmitter and receiver, Voice playback, Relay.

\section{INTRODUCTION}

In everyplace Light can be used in our everyday life. When using of light as a medium to transmit the data it is very high security. So here Light is used as a medium so these technique is called as the Li-Fi Technique. Keypad is used to choose the mode and it is send to the controller. Controller send the command to the Li-Fi Transmitter. Li-Fi transmitter is used to transmit the data through the LEDs and it is received by Li-Fi Receiver with the help of Solar panel. And the solar panel send to the voltage to the $\mathrm{Li}-\mathrm{Fi}$ Receiver. And the receiver connected to controller. When the mode is set to data the controller connected to the Relay. Relay is used to control the device such as fan, light etc,. And if the mode is voice mode the controller connected to the voice playback unit. It is used to store the voice to direct the blind people for indoor navigation. And the Speaker unit is used to deliver the output for the blind people to navigate one place to another place without any disturb. Firstoffall these all are trained to blind person to how to handle these commands in the keypad. Then the blind people to use that for the navigation and device control.

\section{PROBLEM STATEMENT}

For the blind people they may faces lot of unconditional situations in their life. They can't able to survive like a normal human being.

Revised Manuscript Received on April 27, 2020.

* Correspondence Author

Dr Senthamil Selvi M*, Professor \& Head , Department of Information Technology , Sri Ramakrishna Engineering College, Coimbatore

Nivedita S, Student, Department of Information Technology, Sri Ramakrishna Engineering College, Coimbatore

Ramya M, Student, Department of Information Technology , Sri Ramakrishna Engineering College, Coimbatore

Sunija S, Student, Department of Information Technology , Sri Ramakrishna Engineering College, Coimbatore

(C) The Authors. Published by Blue Eyes Intelligence Engineering and Sciences Publication (BEIESP). This is an open access article under the CC BY-NC-ND license (http://creativecommons.org/licenses/by-nc-nd/4.0/)
They also have some defects in their vision. Many of the people they won't help those blind peoples in certain places, in this world there are many populations in everywhere and in that case there were also some blind people may also occur in this certain populations. They feel difficult to travel from certain locations of their places. There are many projects used to help blind peoples but there will be some drawbacks also may occur for those projects. They may not have any of safety purposes. The blind people facing difficulties in both indoor and outdoor navigations, and they can't able to travel or walk by certain locations where they want to reach. In our project the visually impaired people can able to reach certain places by using of indoor navigation. So the visually challenged people they feel comfortable by using indoor places Now a days they were busy in their working schedule and full of busy people and there will crowded one everywhere in their normal life. In that crowded places this visually impaired people they may not able to go on those crowded area, but there are some techniques to overcome those difficulties. This project helps the blinds inside the home of indoor navigation. This visually challenged people will get trained for using this project, so that they can able to go for certain places which will be instructed through this project. It will be guided to go for certain locations in the indoor navigations. This project is only applicable for the indoor navigations purposes. By the help of visible light communications the project works through it, and also helps the blind. By using solar panel the light emits through the medium and projects may works according to indoor navigations. Indoor navigation helps the blind in an easiest way and also able to move through some of the certain places.

\section{III.OBJECTIVES}

The main objective of this project is about indoor navigation for the visually impaired people. They can able to survive by their own for navigating indoor places. It can easily adapt for visually people. This indoor navigation system can help those blind people and can able to move certain places where they would like to reach. They can able to help of their own. The indoor systems have of certain commands for transmitter section and receiver section. In transmitter section, there will be certain commands used for indoor purposes, receiver section is based on audio were certain instructions is given to the audio, so that we can able to navigate to particular places inside the home. This two section is an important one which we used in this project for the blind peoples. 


\section{IV.METHODOLOGY}

The Li-Fi based indoor navigation for blind persons consists of two main divisions. That is Li-Fi Receiver and Transmitter.

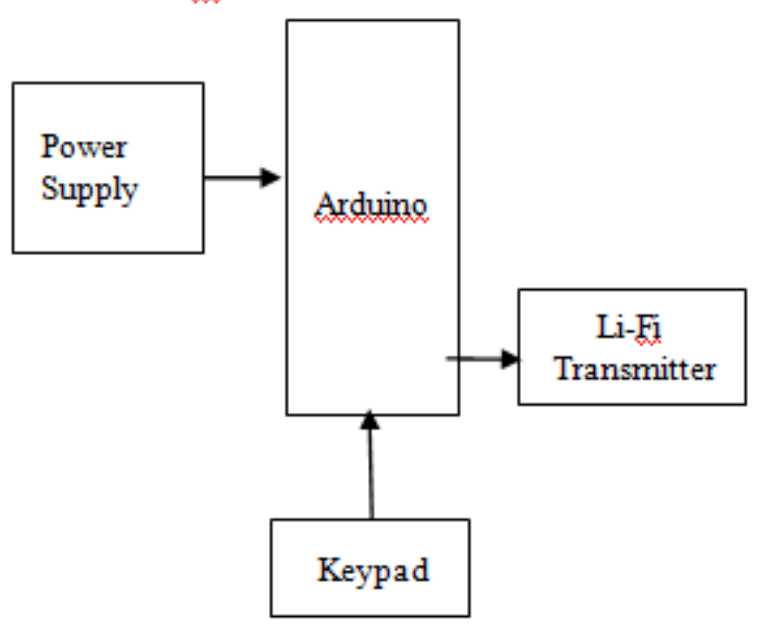

Fig.1 Li-Fi data Transmitter

The transmitter section consists of keypad, Arduino, and Li-Fi transmitter. Fig 1 shows the keypad connected to the Arduino. Here the keypad is used to select the mode of the system. And then the selected data which is in the form of light is transmitted to the solar panel through the $\mathrm{Li}-\mathrm{Fi}$ transmitter.

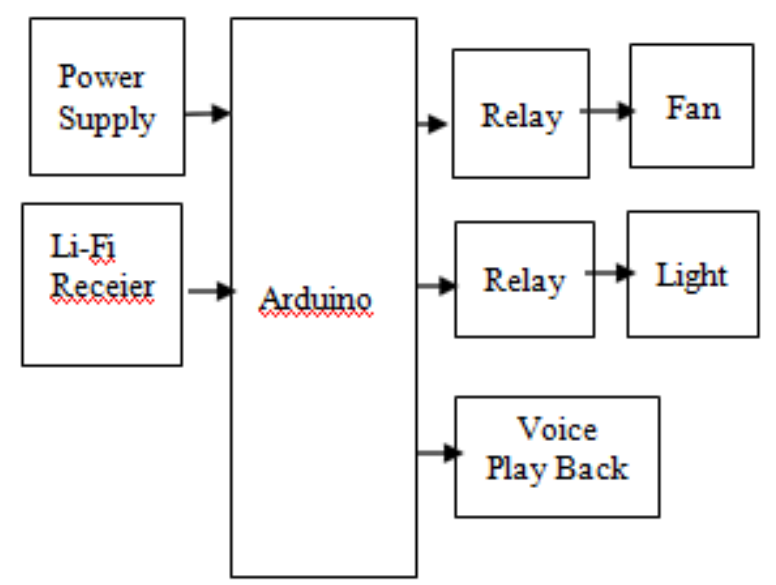

Fig .2 Li-Fi data Receiver

The Li-Fi Receiver section Consists of Li-Fi Receiver, Voice play back, Speaker, Arduino, Relay and device

Fig 2 Shows the solar panel Connected to the $\mathrm{Li}-\mathrm{Fi}$ Receiver. When the system mode is in Voice the output will be attain in tha form of audio through voice play back unit for the navigation. When the system mode is in Data here the device will be controlled with the help of Relay.

\section{SYSTEM DESIGN}

\section{Software Configuration:}

- $\quad$ Arduino IDE 1.5.7

- $\quad$ Embedded C

Hadware Configuration:

- Arduino Uno :It is a type of microcontroller that helps to bulid digital devices and interactive objects that can sense and control objects in physcial world

- LCD : It is used to display the command and display the mode like data mode and voice mode is on or off .

Relay: With the help of Relay the devices like fan, lights, pumps are controlled

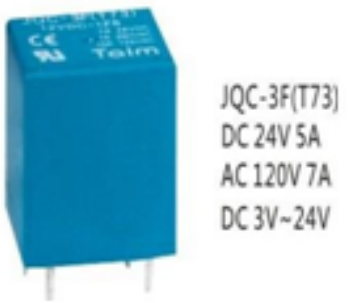

LIFI module: $\mathrm{Li}-\mathrm{Fi}$ receiver and transmitter is used. In Voice mode the input is given in the form of voice and the output is given in the form of audio through speaker .

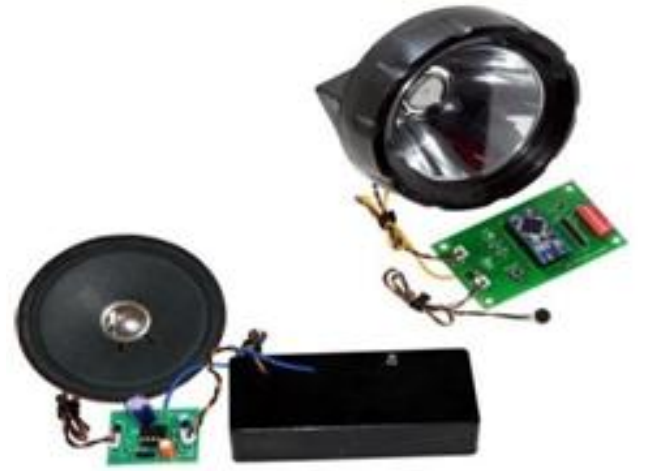

Keypad: keypad helps to switch between data mode and voice mode and its use to implement the modules.

And here the keys are used to choose the command also.

\section{VI.RESULTS AND OUTPUT}

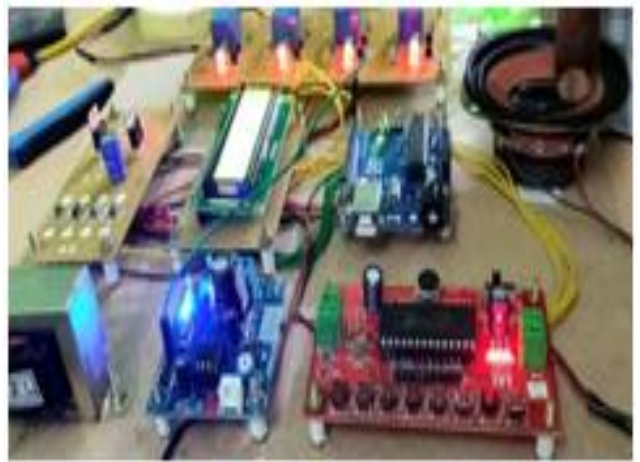

Fig-1: Working of Voice Control part

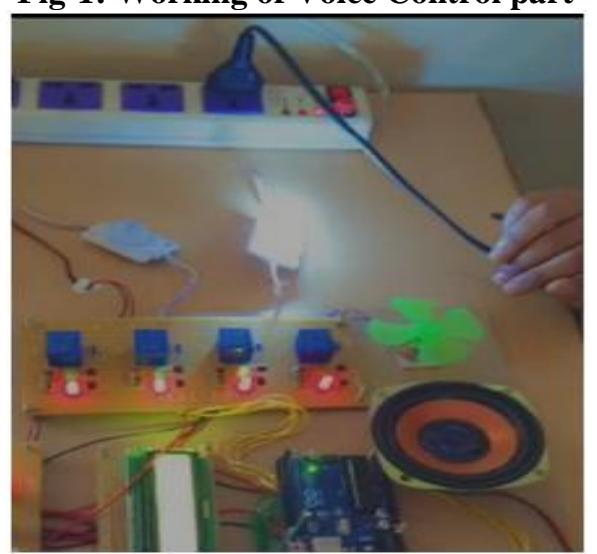

Fig-2: Working of Device Control Part

Published By:

Blue Eyes Intelligence Engineering

\& Sciences Publication

(C) Copyright: All rights reserved.

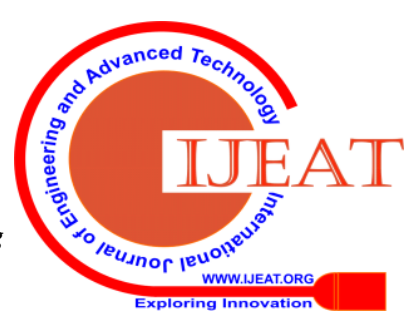


Assistive Technology for visually Impaired people system using to blind people navigate one place to another place in the indoor and control the device without other people help.

\section{CONCLUSION}

This system used for future generation purposes in optical wireless communication. The visible light is used as source for communication and device control as well as audio transmission application. This device helps the blind people to navigate on their own and only used for indoor navigation. By using of transmitter and receiver this system helps to navigate the way. Without any external help they can able to survive by themselves.

$\mathrm{Li}-\mathrm{Fi}$ is an important one which plays an major role in this project. By using the light source which helps the entire part of the system to access and using light source it will be helpful for future projects and communication.

\section{REFERENCES}

1. Shilpa B., Manisha M Shetty., Abhijith Shenoy., Rahul Biddappa, Dhanyashree. "Technology Used for Bind Indoor Navigation System Using Li-Fi”, International Journal of Innovative Research in Engineering, Vol:05,Issue 2,April 2017

2. Subhash Reddy S., Bhaskar Rao Y. "Indoor Navigation System for Blind People Using VLC", International Journal of Engineering and Technology.7 (3.27) (2018) 77-79.

3. Marita R Miranda. "Indoor Navigation System to the Visually Impaired People Using Visible Light Communication Technology”, International Journal of Innovative Research in Computer and Communication Engineering, vol 5, Issue 6, June 2017.

4. Rama Murthy N., Sudha P.N. "Smart Navigation System For Visually Chalanged People", International Journal of Engineering, ISSN: 2347-6982, Issue, sep-2016.

5. Naveen Balaji G., Anusha S., Ashwin J. "GPS Based Smart Navigation For Visually Impaired Using Bluetooth", Imperial Journal of Interdisciplinary Research (IJIR), Vol: 3, Issue 2017.

6. Dianne Pawluk, Nikolaos Bourbakis, Nicholas Guidice, Vincent Hayward, Morton Heller. "Haptic Assistive Technology for Individuals who are Visually Impaired",IEEE Transactions On Haptics, Vol: 8 Issue: July-Septamber2015

7. Sharmila M., Shrin Shifana M., Theebica V., Sangeethapriya V. "Audio Transmission Using Li-Fi Technology", Intrnational Research Journal of Engineering and Technology (IRJET), Volume: 05 Issue:04Apr:2018

8. Sandip Jadhav., Aniket Rathod., Vikram Shinde, "Li-Fi Based Blind Indoor Navigation System" International Research Journal of Engineering and Technology(IRJET), Volume: 05, Issue : Apr 2018.

\section{AUTORS PROFILE}

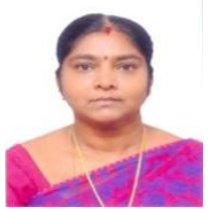

Dr.M.Senthamil Selvi is currently working as Professor \& Head in the Department of Information Technology at Sri Ramakrishna Engineering College, Coimbatore. She has 23 years of teaching experience and 3 years of industry experience.

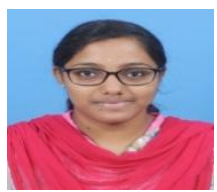

Nivedita.S is currently studying in B.TECH information technology at Sri Ramakrishna Engineering College, Coimbatore.

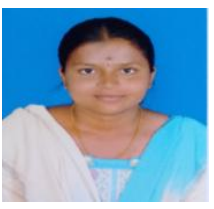

Ramya.M is currently studying in B.TECH information technology at Sri Ramakrishna Engineering College, Coimbatore.

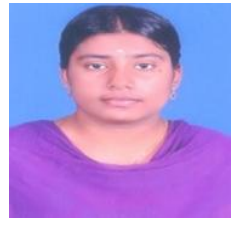

Sunija.S is currently studying in B.TECH information technology in Sri Ramakrishna Engineering College, Coimbatore. 